\section{Legitimidade da representação em instâncias de participação social: o caso do Conselho Estadual de Saúde da Bahia, Brasil}

\author{
The legitimacy of representation in forums with \\ social participation: the case of the Bahia State \\ Health Council, Brazil
}

\author{
Legitimidad de la representación en los foros de \\ participación social: el caso del Consejo de Salud \\ de Bahía, Brasil
}

José Patrício Bispo Júnior 1 Sílvia Gerschman 2

\section{Resumo}

O modelo de representação eleitoral demonstrase insuficiente e inadequado para contemplar os novos formatos participativos, como os exercidos pelos conselheiros de saúde. O artigo analisa a representação e a representatividade no Conselho Estadual de Saúde (CES/BA) da Bahia, Brasil. O estudo foi realizado por meio de entrevistas com 20 conselheiros ou ex-conselheiros de saúde, análise documental das atas e regimentos do CES/BA e observação das reuniões plenárias. Para análise das falas utilizou-se a Técnica de Análise do Discurso. Os resultados são discutidos com base em quatro eixos de análise: processo de escolha do representante pelas entidades; relação estabelecida entre representantes e representados; conformação da representação de interesses no conselho; e critérios utilizados para definição de posicionamentos no plenário. O estudo evidencia um conjunto de problemas referentes à representatividade no CES/BA. São discutidas as peculiaridades da representação nas instâncias de participação social e as dimensões que conferem legitimidade aos representantes.

Health Councils; Social Participation; Health Public Policy
Conselhos de Saúde; Participação Social; Políticas Públicas de Saúde 


\section{Introdução}

A temática da representação ocupa espaço destacado no debate sobre as instâncias de participação social. Embora sejam na atualidade termos fortemente imbricados, a democracia nem sempre esteve associada à representação. Em suas origens, a democracia foi pensada como forma de participação direta dos cidadãos. No entanto, frente à complexidade do mundo contemporâneo, em que a participação de todos os cidadãos em todos os assuntos da sociedade demonstrouse inviável, a representação foi pensada como meio para tornar possível o regime democrático.

Com o advento das novas instâncias de participação social e a criação dos conselhos gestores de políticas foram ampliados os processos de democratização do Estado e de envolvimento dos cidadãos, o que faz emergir novos formatos de representação. Nesse contexto, o modelo de representação eleitoral demonstra-se insuficiente e, por vezes, inadequado para contemplar a abrangência e complexidade dos novos formatos participativos.

No Brasil, a multiplicação de espaços de participação conduziu à transformação da representação política, o que fez transbordar, parcialmente, às fronteiras das eleições. A Sociedade Civil, ainda que de forma não exclusiva, assume a responsabilidade de direcionar e exercer o controle das funções executivas, especificamente em determinadas áreas de políticas sociais. Atores societários passam a desempenhar funções de representação política, mesmo que não tenham sido eleitos pela maioria da população para este fim ${ }^{1}$. Assim, são estabelecidos novos formatos e meios de representação, como os exercidos pelos conselhos de saúde.

Esses conselhos configuram-se como espaços de ampliação da democracia, por possibilitar a inserção de novos atores à cena política, a partir composição plural e paritária dos conselhos. No entanto, o aparato legal, per se, mostra-se insuficiente para garantir a participação e representatividade no âmbito dos conselhos 2. Diversos estudos evidenciam uma série de obstáculos vivenciados no cotidiano dos fóruns participativos, convergindo na constatação da baixa participação de atores sociais, frágil relação entre representantes e representados e relações de poder marcadamente assimétricas 3,4 .

No Estado da Bahia, com a criação do Conselho Estadual de Saúde, em 1991, o setor abre espaços para a democratização das políticas de saúde e incorpora novos atores institucionais à cena decisória. Entidades e movimentos sociais, com reconhecida história de luta em defesa de direitos sociais, passam a fazer parte do conselho e ter a oportunidade de interferir na condução da saúde no estado.

Nesse contexto, os aspectos inerentes à representação e à representatividade dos conselheiros despontam como de fundamental importância para a compreensão da dinâmica do Conselho Estadual de Saúde da Bahia (CES/BA) e para o fortalecimento das instâncias de participação social. Assim, evidenciaram as seguintes questões que balizaram a realização do estudo. Como se legitima a representatividade dos conselheiros? Quais fatores influenciam na postura dos conselheiros e na representação de interesses no âmbito do CES/BA?

Diante desse contexto, o presente artigo tem por objetivo analisar a representatividade e a representação de interesses no CES/BA.

\section{Formas de representação e os instrumentos de legitimidade}

O que se pode entender por representação? Para Piktin ${ }^{5}$, a representação é caracterizada pelo "agir no lugar de", visão complementada por Lavalle et al. ${ }^{1}$ que sugerem como representação o fato de tornar presente alguém ou algo mediante a figura de algum intermediário. Nesse sentido, dois aspectos são apresentados como inerentes à representação: o interesse a ser representado $\mathrm{e}$ a figura do representante como emissário do representado que, por motivos diversos, não pode se fazer presente.

Em sua origem, a representação foi concebida como mecanismo do direito privado. Os representantes ou agentes autorizados agiam em nome dos seus contratantes para interceder com instruções e objetivos bastante específicos. Dentre os vários tipos de representação privada destaca-se o mandato imperativo. Nesse modelo, o representante assume o compromisso e a responsabilidade de defender delimitados interesses do representado. É um tipo de representação em que o representante é mandatário sem qualquer autonomia decisória. O mandato imperativo assegura a linearidade entre vontade do representado e a postura do representante 1 .

No governo representativo, a representação política difere consideravelmente do modelo privado. Isso porque, mesmo que legalmente instituída ou respaldada por mecanismos obrigatórios de autorização, não garante a correspondência entre a ação do representante e a vontade ou interesse dos representados. A relação entre representante e representado caracteriza-se por momentos de aproximação e distanciamento e nem sempre as expectativas dos representados são consideradas. 
Na distinção entre mandato imperativo e mandato representativo, as questões centrais do debate estão entre o controle por parte do representado e a autonomia do representante no desempenho da função.

Dentre as dimensões do processo representativo, a questão da legitimidade apresenta-se como característica de maior relevância para efetivação da representação. Busca-se identificar os fatores que possam conceder legitimidade à representação política. Para Santos \& Avritzer 6 a legitimidade da representação envolve pelo menos três dimensões: autorização, identidade e prestação de contas.

Nas democracias liberais, a autorização assume a primazia da legitimidade da representação e a eleição alcança o status de principal mecanismo de concessão de legitimidade aos representantes eleitos. A democracia ao mesmo tempo em que se expande e se consagra como regime político capaz de possibilitar o envolvimento de todos os cidadãos no processo decisório, também se reduz à dimensão eleitoral e à condição de procedimento para formação de maiorias.

Embora a autorização eleitoral seja essencial para se determinar os limites e a responsabilidade do poder político, ela não nos diz muito a respeito da verdadeira legitimidade da política representativa em uma sociedade democrática 7 . O processo eleitoral, por sua própria natureza, possui limitações para identificação de preferências, definição de prioridades e representação de identidades minoritárias. Em alguns casos, mostra-se como mecanismo ultrapassado para conferir legitimidade ao representante.

Ao se debruçar sobre as novas formas de participação e representação, Avritzer 8 destaca que diferentes mecanismos de autorização, além da forma eleitoral, concedem legitimidade à representação. $\mathrm{O}$ autor classifica em três tipologias os papéis políticos dos representantes: o de agente; o de advogado; e o de partícipe. É importante destacar que nos três casos há o elemento central da representação, "agir no lugar de", todavia o papel desempenhado varia de perspectiva e pode ser legitimado de diferentes maneiras.

A representação do agente é a típica representação escolhida por processo eleitoral. A legitimidade é justificada pelo voto como ato de autorização. Nesse processo, é conferido mandato aos candidatos mais votados que assumem o papel de representar os interesses da massa eleitoral.

O papel político do advogado ou ativista de causas públicas ou privadas prescinde da escolha do indivíduo ou grupo representado. $\mathrm{O}$ ativista não é escolhido ou autorizado a falar em nome de quem representa. Quem elegeu a Anistia In- ternacional como defensora dos direitos humanos ou defensora de pessoas que nem sabem que tal organização existe? Quem conferiu poder ao Greenpeace para se constituir em defensor internacional das questões ambientais? Questões desse tipo são ainda mais problemáticas quando se pensa nas organizações que defendem a autonomia e o direito das mulheres em países nos quais elas não têm direitos e, se consultadas, provavelmente diriam que não são a favor destes direitos 8 .

Nesses casos, não existe processo de autorização formal, nem monopólio da representação e nem territorialidade. O que confere legitimidade é a afinidade com o tema ou identificação com a situação de exclusão, de abandono ou de padecimento que o representante julga ser injusta e reversível. Assim, o elemento central da legitimidade não é a autorização e sim a identificação com a causa ${ }^{8}$.

O terceiro tipo, o papel político do partícipe, é o típico caso de representação da Sociedade Civil. Sua principal característica é o domínio do conhecimento sobre o tema. Assim, a experiência e a especialização definem essas entidades como representantes dos interesses da Sociedade Civil. Um bom exemplo é a representação exercida pela Associação Brasileira de Saúde Coletiva (ABRASCO), que representa os interesses da comunidade técnico-científica sobre os temas relacionados às políticas de saúde e à Saúde Coletiva. O que confere legitimidade a essa entidade é a história da militância em defesa da causa e a experiência acumulada em sua trajetória. A legitimidade é justificada não pela eleição ou voto na entidade, mas sim pela identidade com a causa e, sobretudo, a trajetória do representante.

No âmbito dos conselhos de saúde, nenhum dos tipos de representação se adéqua de maneira exclusiva. A representação no conselho é difusa e busca confluir características da atuação institucional e da mobilização social ${ }^{9}$. Embora os representantes do conselho devam ser eleitos, a comunidade eleitoral de cada uma das entidades representadas possui características muito peculiares e pode apresentar-se difusa ou restrita aos associados ou partícipes daquela entidade.

\section{Metodologia}

O presente trabalho caracteriza-se como estudo de caso com níveis de análise imbricados 10 , em que o campo de estudo foi constituído pelo CES/BA.

As fontes de informações que subsidiaram a presente investigação foram entrevistas semiestruturadas, observação participante e análise 
documental. A utilização dessas múltiplas fontes objetivou promover a triangulação dos dados na perspectiva de melhor apropriação do fenômeno da participação no CES. Para Flick 11, a combinação das técnicas de observação participante, entrevista e análise de documentos apresenta grande potência para a interpretação e desvelamento de fenômenos sociais complexos. O recorte temporal do trabalho foi delimitado entre os anos de 2003 e 2011.

Foram entrevistados vinte conselheiros e exconselheiros estaduais de saúde, dos quais: sete representantes de usuários; quatro dos profissionais de saúde; cinco prestadores públicos e privados; e quatro gestores. As entrevistas foram guiadas por um roteiro previamente definido e foram realizadas entre janeiro e abril de 2012. As mesmas foram gravadas em aparelho de áudio digital e posteriormente transcritas. Deve-se destacar que a entidade/segmento do representante diz respeito ao período em que o mesmo foi conselheiro estadual de saúde, o que não necessariamente coincide com a função ou área de atuação no momento da entrevista. Isso porque existem casos de sujeitos que foram conselheiros estaduais, em períodos passados, representando determinados segmentos, e no período da entrevista atuavam em outras funções, seja no governo ou em outra entidade social. A escolha dos entrevistados foi fundamentada no critério intencional, determinado pelo protagonismo do conselheiro ou de suas posições frente aos encaminhamentos e posturas do CES/BA.

Para seleção dos sujeitos foram utilizadas diversas estratégias de identificação destes informantes. No primeiro momento, realizou-se análise da frequência dos conselheiros às reuniões plenárias, entre 2003 e 2011, para identificar os indivíduos mais assíduos. Em seguida foi realizada a análise das atas das reuniões, com identificação dos pontos de maior tensão e embates nas reuniões plenárias. Nesse sentido, foram identificados os conselheiros que tiveram atuação de maior destaque no decorrer dessas discussões, seja no apoio ou oposição às propostas de governo. Com base na análise das atas, em conversas com os próprios conselheiros de saúde e com servidores da Secretaria Executiva do conselho, foram identificados conselheiros e ex-conselheiros que tiveram atuação destacada dentro do período de análise da pesquisa.

A técnica de análise documental foi escolhida em função dos documentos terem a capacidade de desvelar a situação e o contexto em que foram produzidos, além de explicitar os valores culturais e ideológicos que motivaram e determinaram sua produção ${ }^{11}$. Os documentos analisados foram: atas das reuniões plenárias do CES/
BA; resoluções do CES/BA; regimentos internos; relatórios de gestão da Secretaria de Saúde do Estado da Bahia (SESAB); e leis, portarias e decretos da SESAB, que guardaram relação com a atuação do CES/BA.

A técnica de observação participante foi utilizada, especialmente, no intuito de desvelar conflitos, posturas assumidas e regras de convívio estabelecidas entre os conselheiros. Realizou-se observação das reuniões plenárias do conselho no período de um ano, entre maio de 2011 e abril de 2012. O registro dos fatos observados e das impressões do pesquisador sobre a dinâmica estabelecida foi realizado em diário de campo, utilizado também como fonte de dados durante a análise. Além das reuniões plenárias, também foi realizada observação durante a VIII Conferência Estadual de Saúde da Bahia, ocorrida em setembro de 2011.

A análise das entrevistas foi realizada em duas fases distintas e complementares. A primeira, foi constituída por tratamento do material e identificação das categorias temáticas conforme técnica proposta por Bardin 12 . No segundo momento, a análise propriamente dita, foi realizada pela técnica de Análise do Discurso 13 .

$\mathrm{Na}$ análise buscou-se identificar as três dimensões analíticas do discurso: (a) Relação de Força: lugar social e posição relativa do locutor e do interlocutor; (b) Relação de Sentido: a interligação entre este e os vários discursos; e (c) Relação de Antecipação: experiência ante projetada do locutor em relação ao lugar e à reação de seu ouvinte 14.

Baseando-se no processamento e análise das informações, emergiram quatro categorias temáticas, com suas respectivas dimensões, relacionadas à legitimidade da representação e aos fatores que influenciam na postura dos conselheiros e na representação de interesses no âmbito do CES/BA. Essas categorias foram evidenciadas com base nos vários conteúdos presentes no material discursivo e que guardavam relação com o objetivo do artigo e as questões da investigação.

Para a realização da pesquisa foi solicitada autorização formal ao CES/BA. O projeto de pesquisa foi apreciado pelo Comitê de Ética em Pesquisa da Escola Nacional de Saúde Pública Sergio Arouca, da Fundação Oswaldo Cruz (CEP/ENSP) e aprovado conforme protocolo no $151 / 2011$. Foram obedecidas todas as recomendações éticas da Resolução no 466/2012 15.

\section{Resultados e discussão}

Os eixos da análise foram constituídos pelas seguintes categorias: processo de escolha do 
representante pelas entidades; relação estabelecida entre os representantes e as entidades; conformação da representação de interesses no âmbito do conselho; critérios utilizados para definição de posturas e posicionamentos no plenário do CES/BA.

\section{Escolha dos representantes para o CES/BA}

Os resultados evidenciam diferentes meios de escolha dos representantes, com o predomínio de três formatos principais. Uma das modalidades é a que o presidente da entidade assume naturalmente a representação no conselho. Esse modelo foi observado principalmente entre os representantes dos profissionais de saúde, em que os presidentes do Sindicato dos Médicos e do Sindicato dos Servidores Estaduais em Saúde assumiam a representação de suas entidades no CES/BA. “A prática nossa no SINDSAÚDE sempre foi o representante do SINDSAÚDE no conselho ser o presidente" (Entrevista 05).

Outro critério de seleção consiste na escolha do representante por parte do corpo dirigente da entidade. Esse método foi o mais utilizado pelas instituições para a escolha dos representantes, especialmente entre os prestadores e os usuários. Nesse formato não há envolvimento das bases ou realização de assembleias para eleição do representante. A cúpula da instituição decide internamente o nome do conselheiro a ser indicado, que pode ser um membro da própria diretoria ou outro filiado/associado. A indicação é motivada por destaque pessoal no interior da organização, associada à confiança que a direção mantém sobre esses indivíduos.

"Fui escolhido entre os membros da associação dos sindicatos dos hospitais. Através da sua diretoria fizeram a indicação. Então, foi um consenso entre suas entidades e sua diretoria, não houve assim uma assembleia geral com essa finalidade" (Entrevista 14).

O terceiro método de escolha foi a eleição em assembleia ou reunião do corpo de filiados da entidade. Embora esse possa parecer o critério mais democrático e natural para escolha da representação, observa-se que poucas foram as entidades que publicizaram entre os seus membros o processo de eleição para representante no CES/BA. Tal situação era motivo de insatisfação e questionamento sobre a representatividade dos conselheiros oriundos de entidades sociais. “Tem algumas áreas, principalmente na área de sindicatos e associações, que poucos faziam uma eleição democrática pra poder indicar as pessoas que iriam fazer parte do conselho. Geralmente, as mesmas instituições mandavam sempre o nome das mesmas pessoas" (Entrevista 17).
A pequena transparência nos critérios de escolha dos representantes é também evidenciada em outros estudos sobre o tema 9,16. Em municípios do Estado do Rio de Janeiro, identificou-se a baixa visibilidade nos mecanismos utilizados para a eleição dos representantes dos usuários nos conselhos de saúde 9 . Embora também tenha sido observado um cenário de representação difusa, com a escolha de representantes por múltiplos métodos, a autora sugere que, para a maioria dos casos, não são as comunidades que escolhem seus representantes, mas as cúpulas dirigentes que designam seus indicados no conselho. Para Labra 17, as associações da sociedade civil muitas vezes replicam em seu interior os mesmos traços autoritários e excludentes ainda prevalentes na sociedade brasileira, constituindo-se em instâncias pouco democráticas.

Além da baixa transparência, foram identificados outros problemas relativos ao processo de eleição dos conselheiros. Um deles refere-se à distorção da representação, com a indicação de alguns conselheiros para a representação dos usuários, mas que na verdade eram pertencentes a outros segmentos. Como exemplo, a representante das Obras Sociais de Irmã Dulce, maior prestador privado do SUS na Bahia, fez parte do conselho na representação dos usuários por indicação da Associação Comercial da Bahia. Por sua vez, o representante da Federação dos Trabalhadores da Agricultura (FETAG) ocupou no conselho por seis anos uma vaga no segmento dos usuários, no entanto este conselheiro é trabalhador em saúde, da categoria dos agentes comunitários, e inclusive faz parte da entidade sindical destes profissionais.

Embora, de acordo com os princípios do SUS, todos devam ser considerados usuários, no âmbito dos conselhos de saúde os segmentos de gestores, profissionais e prestadores possuem assentos próprios na composição do pleno. A ocupação das vagas dos usuários por representantes que fazem parte, identificam-se e militam em outros segmentos, tende a causar grave distorção nos critérios de paridade e afetar a correlação de forças no interior dos conselhos.

Outra irregularidade decorre do fato de que alguns conselheiros exerceram múltiplos mandatos consecutivos na representação da mesma entidade. "Eu já tô na minha quarta recondução no conselho estadual. Exatamente, oito anos que tô no conselho" (Entrevista 06). Tal situação vai ao encontro do preconizado pelo regimento interno do CES/BA, que estabelece o período de mandato do conselheiro em dois anos, sendo possível uma única recondução por igual período.

Desse modo, os critérios de escolha pouco democráticos, a distorção na representação e a 
manutenção do mesmo conselheiro por muitos mandatos são indicativos da frágil representatividade, com implicações na dinâmica do CES/ BA. Os problemas da representatividade implicam baixo desempenho das instâncias participativas, por conduzir a atividade dos participantes em desconexão com os grupos representados e desencadear na atuação dos representantes com carência de força política 18. Para Santos et al. ${ }^{19}$, a manutenção de um grupo restrito de atores constitui um processo elitista de participação social, o que pode indicar forte razão para o distanciamento de outros personagens com capacidade de contribuir na elaboração das políticas públicas.

\section{Relação representante, entidade e os grupos representados}

Ao analisar as relações estabelecidas entre os conselheiros de saúde e suas respectivas entidades, observa-se a existência de distanciamento e pouca articulação entre os representantes e as comunidades representadas. Todos os entrevistados relataram dificuldades em manter articulação com suas bases, em decorrência principalmente da desmobilização e desinteresse dos pares.

Os representantes da Sociedade Civil, em sua maioria, referiram que as entidades não oferecem subsídios para a ação dos conselheiros, tampouco demonstram interesse sobre o trabalho do CES/BA ou sobre a situação da política de saúde do estado. Muitos afirmaram que as diretorias fazem questão de manter a vaga da instituição no conselho estadual pelo status que isto significa e pelo potencial poder de inserção no governo, no entanto, não valorizam as atividades do conselho.

“Rapaz, a própria entidade não acompanha e deixa de lado a discussão, não se interessa, não prioriza. Eu participava de reunião, de curso, de seminário, tinha a preocupação de fazer um relatório, encaminhar um relatório, e a direção não dizia nada sobre isso, nada. Era como se eu não tivesse feito nada" (Entrevista 01).

"Eu notei que a CUT teve ausente de todo o meu processo. (...) A CUT não tava nem aí pra representação da central no conselho, né?" (Entrevista 04).

Se as relações com as diretorias são frágeis, ainda mais distante está o contato dos conselheiros com as bases das entidades representadas. A maioria dos representantes mantém pouquíssimos contatos com os filiados ou associados das instituições, conforme evidenciado: "Na realidade não existe em si uma aproximação, não chega às bases as propostas discutidas no conselho" (Entrevista 16).
Os assuntos referentes ao CES/BA, na maioria das vezes, não são tratados nas assembleias ou plenárias das entidades. E, de maneira geral, não há mecanismo de ausculta dos pares ou discussões sobre os temas abordados no conselho.

Os resultados referentes ao processo de escolha dos representantes e as relações estabelecidas entre estes, as entidades e os grupos representados sugerem a existência de fragilidades na representação dos conselheiros. No entanto, não é possível avaliar a representação nas instituições participativas apenas pelos critérios da representação eleitoral.

De acordo com Avritzer 8, a representação realizada por atores da Sociedade Civil nas instituições participativas, a exemplo dos conselhos de saúde, é bastante diferente da representação eleitoral clássica. Para Lüchmann 20, a representação exercida nos conselhos gestores difere da representação eleitoral por esboçar uma ideia difusa do representado, que muitas vezes não está restrito a um determinado território, segmento ou classe social.

Nesse sentido, a legitimidade da representação da Sociedade Civil extrapola a questão se o representante foi ou não eleito no interior de suas entidades. Embora o envolvimento dos afetados pela política deva sempre ser estimulado e valorizado, nem sempre isto é possível. Em muitos casos, essas entidades não possuem vínculos com os grupos representados, e a escolha ocorre em função de sua expertise e qualificação 21 .

O processo de escolha realizado em assembleias ou plenárias das entidades constitui um mecanismo amplamente defendido como democrático e participativo. No entanto, apesar de conferir maior organicidade com as bases, esse tipo de representação apresenta também limitações, por manter-se circunscrito àqueles que estão mobilizados 22 . Ou seja, os critérios de escolha ficam limitados aos que têm interesse e/ou oportunidade de participar da militância política da entidade. Isso não significa que as vozes ali presentes ou os interesses manifestados correspondam aos interesses de todos os que vão ser afetados pela política, o que sugere também limitações na representatividade desse método de escolha.

Desse modo, se evidencia a limitação do processo eleitoral frente aos novos formatos de representação da Sociedade Civil. Assim, o problema em questão é o que pode conferir legitimidade a esses representantes.

Nesse contexto, a identificação com a causa e a agregação de solidariedades se apresentam como fatores muito mais legítimos do que o monopólio territorial e a autorização formal. Para esses casos, o "agir no lugar de" é respeitado, no 
entanto varia de perspectiva e pode ser justificado de diferentes maneiras. A depender do tipo de representação, a legitimidade pode ser conferida pela identidade e solidariedade com a causa, como também pelo domínio e afinidade sobre o tema 23

No entanto, deve-se destacar que a existência de outros mecanismos de legitimidade não significa que deva ocorrer o insulamento dos representantes e o distanciamento das suas entidades de origem. A representação nos conselhos de saúde é tipicamente resultante do processo de ampliação da participação da sociedade no processo decisório. Dessa forma, a participação e o envolvimento comunitário devem ser cada vez mais estimulados, no sentido de aglutinar os diversos mecanismos de legitimidade e potencializar os espaços de participação da sociedade.

A combinação de múltiplas formas de representação, com suas respectivas legitimidades, é requisito necessário ao processo de ampliação da democracia e da representação política. Nesse sentido, para os conselhos de saúde vislumbramse a coexistência e a complementaridade entre as formas de participação e representação.

\section{Representação de interesses entre os conselheiros de saúde}

Os resultados evidenciaram um padrão de comportamento dos representantes na defesa de três níveis de interesse: interesses individuais; interesses corporativos ou institucionais; e interesses amplos sobre as políticas de saúde.

Os interesses individuais caracterizavamse pelo fato dos representantes buscarem benefícios pessoais ou destaque individual de sua participação no conselho. Foi relatado que muitos conselheiros tinham sempre "necessidade de aparecer" ou queriam sempre fazer parte de todas as atividades demandadas pelo plenário, como: eventos fora do estado; participar de comissões; ou mesmo assumir a relatoria das prestações de contas.

Outra característica desse tipo de representação de interesses diz respeito aos posicionamentos assumidos nas discussões e votações em plenário, em que os representantes adotavam posturas baseados em seus interesses individuais, sem levar em conta os interesses gerais ou mesmo do grupo representado. $\mathrm{O}$ discurso a seguir caracteriza a predominância dos interesses individuais sobre os coletivos: "A representação era muito personificada. Então, primeiro a pessoa achava que ela tava ali pra cuidar dos interesses dela, independente da entidade. Se os interesses dela também beneficiassem a entidade, ótimo pra entidade, se não, paciência" (Entrevista 01).
Os interesses corporativos, segundo nível de representação, foram os mais frequentes e os mais destacados pelos conselheiros. Nesse caso, os representantes assumiam no conselho a postura de acirrada defesa dos interesses do seu segmento, desvirtuando-se das questões gerais sobre a saúde da população. Evidenciou-se também uma velada disputa entre alguns representantes sociais, com o propósito de conseguir inserir na discussão do conselho os assuntos relativos à sua categoria.

"Defesas muito mais corporativas, não tenho a menor dúvida. Tinham defesas da política estadual de saúde? Tinham, existiam essas defesas. Mas, se fazia muito mais defesas corporativas do que estruturantes de políticas de saúde. Então, era a categoria 'A' fazendo seu bloco na defesa de uma proposta que era favorável à sua corporação, né?" (Entrevista 18).

O que observou-se foi o estabelecimento de uma lógica de fragmentação de interesses que, muitas vezes, sobrepunha a demanda dos grupos específicos sobre a necessidade de saúde da população. Os grupos apontados como os que mais tencionaram na defesa de sua pauta específica foram os trabalhadores em saúde e os representantes de patologias.

"Pra mim tá muito claro de que a pauta sindicalista, nesse exato momento, é apenas salário e a questão do plano de carreira. Então assim, em certos momentos isso se torna uma pauta acima de tudo e outras pautas são relegadas ao segundo plano" (Entrevista 07).

“Então, representantes lá das hepatites só querem falar das hepatites; representantes dos renais crônicos só querem falar dos renais crônicos. E isso gera uma fragilidade que acaba levando para uma maior passividade em relação à discussão das políticas de um modo geral" (Entrevista 11).

O terceiro tipo de representação de interesses correspondeu à posição em defesa da melhoria do estado de saúde da população e do desenvolvimento de políticas de saúde amplas e resolutivas. Nesse caso, os interesses pessoais e corporativos foram relativizados frente à importância das questões abrangentes sobre o SUS e a qualidade da saúde no estado. É o típico caso da predominância do interesse geral sobre as especificidades das partes. $\mathrm{O}$ discurso a seguir ilustra tal posicionamento: “O meu compromisso não é só com a CUT, não é só com a minha entidade sindical, mas é com todo o processo político de construção de uma sociedade justa, de construção do SUS, tá entendendo?" (Entrevista 04).

Vale ressaltar que esses três tipos de representação de interesses não eram excludentes entre si. A realidade observada demonstrou que, muitas vezes, os representantes não mantinham 
apenas um desses três níveis de interesse. Ou seja, o mesmo representante, a depender da conjuntura e da correlação de forças estabelecida, poderia se posicionar motivado por interesses pessoais, das corporações ou em defesa da ampliação do nível de saúde da população. Mesmo que alguns conselheiros demonstrassem maior inclinação para posicionamentos individuais ou corporativos, isto não significa que agiam motivados apenas por estes tipos de interesses.

\section{Em que os conselheiros se baseiam para} definir suas posições

Os entrevistados, em sua maioria, referiram que definem suas posturas com base na consciência individual e da própria avaliação do que seria mais adequado para a elaboração da política de saúde. A principal razão alegada para utilização de critérios pessoais foi a necessidade de autonomia dos representantes para a tomada de posições no exercício do mandato.

"Minha postura é embasada na minha consciência, isso eu acho que é correto, é fundamental. Ou seja, eu fui escolhido, mas eu não fui escolhido com uma camisa de força no sentido de que você tem que fazer isso aqui. Não pode ser assim. Foi um voto de confiança das pessoas que me escolheram e eu exerço meu papel com base, enfim, nos valores e no que eu acho que são corretos" (Entrevista 11).

Por sua vez, os posicionamentos de outros representantes eram embasados quase que exclusivamente nas orientações da instituição representada, com pouca liberdade para assumir postura diferente do estabelecido pela entidade. “ A posição era sempre a mesma, que era uma posição da instituição, não era a posição da pessoa, né?" (Entrevista 18).

Nesse modelo, mesmo que do ponto de vista pessoal o representante não concordasse com determinados encaminhamentos ou ações a serem implementadas, este se posicionava sempre em defesa do interesse da instituição. O relato do entrevistado demonstrou a situação de constrangimento e coerção que moldava o posicionamento dos conselheiros ligados à gestão: "Na hora que vocêfaz o argumento, às vezes, você até toca a pessoa de outra forma. Mas, as coisas são tão discutas lá nas estruturas mais elevadas, se bate tanto da necessidade de ser daquela forma que o cara vai lá e não tem jeito. Você pode falar o que for, ele pode achar que é interessante, que é importante, que é até melhor para população, mas na hora do voto é com o governo" (Entrevista 01).

Esses achados remetem à discussão sobre a dualidade dos tipos de mandatos: impera- tivo e representativo. Nos dois tipos, a questão central estabelecida é a dualidade entre a possibilidade de controle exercida pelo representado e a autonomia do representante para o exercício do mandato.

Para Manin et al. 24, a representação por mandato necessita ser aprofundada e ampliada, pois o mecanismo de mandato imperativo apresenta debilidades por não levar em consideração a dinâmica do processo político, sempre sujeito a intempéries. A depender de mudanças nas conjunturas política, econômica ou social, seguir fielmente os compromissos assumidos pode significar malefícios para o público em geral ou mesmo para o segmento especificamente representado.

E mesmo que não haja mudança de conjuntura, seria justo ou aceitável um representante viabilizar benefícios para um determinado grupo social, diante de privações ou prejuízos para o total da população? Assim, é possível inferir que a representatividade não pode ser avaliada apenas levando-se em consideração a fidelidade das ações do representante frente aos compromissos assumidos com os representados 25 .

Urbinati 7 destaca que embora o formato representativo tenha viabilizado o regime democrático para o mundo contemporâneo, a relação entre representantes e representados é problemática. Isso porque as expectativas da população e as realizações de seus representantes jamais irão corresponder com exatidão. Para a autora, os líderes e representantes ao invés da imparcialidade desvinculada das influências sociais são vulneráveis a elas. Nesse sentido, a representação será sempre afetada por forças exógenas divergentes da vontade dos eleitores.

Os conselhos de saúde são por excelência o espaço da discussão e da deliberação. Trata-se de um colegiado em que a argumentação e a avaliação das propostas apresentadas constituem um requisito necessário para o aprimoramento das ações e a definição das políticas.

O que justifica a deliberação pública é a natureza diversificada do organismo representativo, e não a existência de uma imutável convicção prévia e impermeável ao debate dos representantes 22 . Nesse sentido, a adoção do mandato imperativo é considerada inadequada para o exercício da representação no âmbito dos conselhos de saúde, por não possibilitar a autonomia e liberdade do representante para ceder em determinadas negociações ou priorizar questões gerais em detrimento dos interesses dos segmentos específicos.

Mas, se por um lado não pode existir controle total dos representados sobre o representante, por outro, não é razoável a completa indepen- 
dência e ausência de mecanismos de acompanhamento do conselheiro. Assim, a melhor alternativa para o dilema controle versus autonomia é a busca do equilíbrio entre estes dois polos. Ao se privilegiar um dos dois extremos, ocorrerá a total ausência de controle das ações dos representantes ou o esvaziamento do conteúdo político da representação como mecanismo responsável por organizar o governo e promover o bem-estar coletivo 1 .

Diante desse dilema, como pode então ser garantida na prática cotidiana a representatividade nos conselhos de saúde? Conforme destaca Gerschman 9, a representação nas instâncias participativas é difusa e busca confluir características da representação institucional com mecanismos de mobilização social. Assim, a representatividade das organizações da Sociedade Civil exige uma indissociável ligação entre representação e participação.

Para as instâncias participativas - como o próprio nome evoca - a representatividade só pode ser assegurada mediante o envolvimento e a participação da população. Lüchmann 20 adverte que a qualidade e a legitimidade da representação vão depender do grau de articulação e organização da Sociedade Civil. Segundo o autor, a participação constitui um fator chave para a boa representação.

Assim, para as instâncias de participação social, além dos mecanismos clássicos de legitimidade, que devem ser assegurados sempre quando possível, a representatividade vai estar sempre garantida em um contexto de ativa mobilização das comunidades e de proximidade do representante com a base representada.

\section{Resumen}

El modelo de representación electoral resulta insuficiente e inadecuado para hacer frente a los nuevos formatos participativos, como por ejemplo el ejercido por los Consejos de salud. El artículo analiza la legitimidad de la representación en el Consejo de Salud del Estado de Bahía, Brasil. El estudio se realizó a través de entrevistas con 20 consejeros y ex-consejeros de salud, un análisis documental de actas y reglamentos del consejo y la observación de las sesiones plenarias. Para el análisis se utilizó la técnica de análisis del discurso. Los resultados se discuten a partir de cuatro líneas de análisis: procedimiento para la selección de consejeros de las entidades; relación entre representantes y representados; conformación de la representación de intereses en el consejo; $y$ los criterios utilizados para definir las posiciones adoptadas. El estudio demuestra una serie de cuestiones relativas a la representación en el Consejo de Salud del Estado de Bahía. Se discuten las peculiaridades de la representación en foros de participación y las dimensiones que dan legitimidad a los representantes sociales.

Consejos de Salud; Participación Social; Políticas Públicas de Salud 


\section{Colaboradores}

J. P. Bispo Júnior participou da concepção do estudo, coleta e análise de dados, redação do artigo e revisão da versão final. S. Gerschman participou da concepção do estudo, análise dos dados e revisão da versão final do artigo.

\section{Referências}

1. Lavalle AG, Houtzager PP, Castello G. Democracia, pluralização da representação e sociedade civil. Lua Nova 2006; 67:49-103.

2. Bispo Júnior JP, Gerschman S. Potencial participativo e função deliberativa: um debate sobre a ampliação da democracia por meio dos conselhos de saúde. Ciênc Saúde Coletiva 2013; 18:7-16.

3. Bispo Júnior JP, Sampaio JJC. Participação social em saúde em áreas rurais do Nordeste do Brasil. Rev Panam Salud Pública 2008; 23:403-9.

4. Cotta RMM, Martins PC, Batista RS, Franceschinni SCC, Priore SE, Mendes FF. O controle social em cena: refletindo sobre a participação popular no contexto dos Conselhos de Saúde. Physis (Rio J.) 2011; 21:1121-37.
5. Pitkin HF. The concept of representation. Los Angeles: University of California Press; 1978.

6. Santos BS, Avritzer L. Introdução: para ampliar o cânone democrático. In: Santos BS, organizador. Democratizar a democracia: os caminhos da democracia participativa. 3a Ed. Rio de Janeiro: Editora Civilização Brasileira; 2005. p. 39-82.

7. Urbinati N. O que torna a representação democrática? Lua Nova 2006; 67:191-228.

8. Avritzer L. Sociedade civil, instituições participativas e representação: da autorização à legitimidade da ação. Dados Rev Ciênc Sociais 2007; 50:443-64.

9. Gerschman S. Conselhos Municipais de Saúde: atuação e representação das comunidades populares. Cad Saúde Pública 2004; 20:1670-81. 
10. Yin RK. Estudo de caso: planejamento e métodos. 4a Ed. Porto Alegre: Bookman; 2010.

11. Flick U. Desenho na pesquisa qualitativa. Porto Alegre: Editora Artmed; 2009.

12. Bardin L. Análise de conteúdo. 5ạ Ed. Lisboa: Edições 70; 2009.

13. Orlandi EP. Análise de discurso. 8ạ Ed. Campinas: Pontes; 2009.

14. Orlandi EP. A linguagem e seu funcionamento: as formas de discurso. 5a Ed. Campinas: Pontes; 2009.

15. Conselho Nacional de Saúde. Resolução no 466, de 12 de dezembro de 2012. Diário Oficial da União 2013; 13 jun.

15. Vieira M, Calvo MCM. Avaliações das condições de atuação dos conselhos municipais de saúde no Estado de Santa Catarina. Cad Saúde Pública 2011 27:2315-26.

16. Labra ME. Conselhos de Saúde do Estado do Rio de Janeiro: complexidade e paradoxos do controle social. In: Ugá MAD, Sá MC, Martins M, Braga Neto FC, organizadores. A gestão do SUS no âmbito estadual: o caso do Rio de Janeiro. Rio de Janeiro: Editora Fiocruz; 2010. p. 89-118.

17. Draper AK, Hewitt G, Rifkin S. Chasing the dragon: developing indicators for the assessment of community participation in health programmes. Soc Sci Med 2010; 71:1102-9.
18. Santos FAS, Souza IMC, Gurgel IGD, Bezerra AFB, Barros NF. Política de práticas integrativas em Recife: análise da participação dos atores. Rev Saúde Pública 2011; 45:1154-9.

19. Lüchmann LHH. A representação no interior das experiências de participação. Lua Nova 2007; 70:139-70.

20. Pinto ICM, Teixeira CF. Formação da política de gestão do trabalho e educação na saúde: o caso da Secretaria Estadual de Saúde da Bahia, Brasil, 2007-2008. Cad Saúde Pública 2011; 27:1777-88.

21. Müller Neto JS, Artmann E. Discursos sobre o papel e a representatividade de conferências municipais de saúde. Cad Saúde Pública 2014; 30:68-78.

22. Avritzer L. A participação social no Nordeste. In: Avritzer L, organizador. A participação social no Nordeste. Belo Horizonte: Editora UFMG; 2007. p. 15-44.

23. Manin B, Przeworski A, Stokes SC. Eleições e representação. Lua Nova 2006; 67:105-38.

24. Edwards KT. Methods of legitimation: how ethics committees decide which reasons count in public policy decision-making. Soc Sci Med 2014; 113: 34-41.

Recebido em 31/Mai/2014

Versão final reapresentada em 09/Set/2014

Aprovado em 22/Set/2014 